\title{
White Privilege \& Why NICUs Should Care
}

Deb Discenza

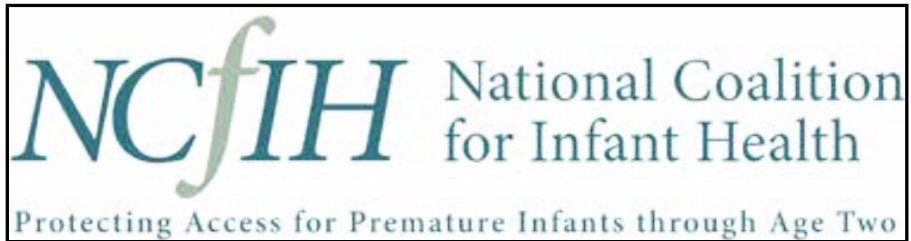

The National Coalition for Infant Health is a collaborative of more than 200 professional, clinical, community health, and family support organizations focused on improving the lives of premature infants through age two and their families. NCflH's mission is to promote lifelong clinical, health, education, and supportive services needed by premature infants and their families. NCfIH prioritizes safety of this vulnerable population and access to approved therapies.

"In the year 2020, where COVID showed the realities of the disparities among African American families, the brutality of those disparities, and the racism on which they were created, the Alliance for Black NICU Families was our part of making infrastructural change specifically in the NICU parent and professional communities ongoing."

In late December, I received our new non-profit designation letter from the IRS. The Alliance for Black NICU Families (https://BlackNICUFamilies.org) was in place. My co-founder, Ashley Randolph, celebrated with me by phone. In the year 2020, where COVID

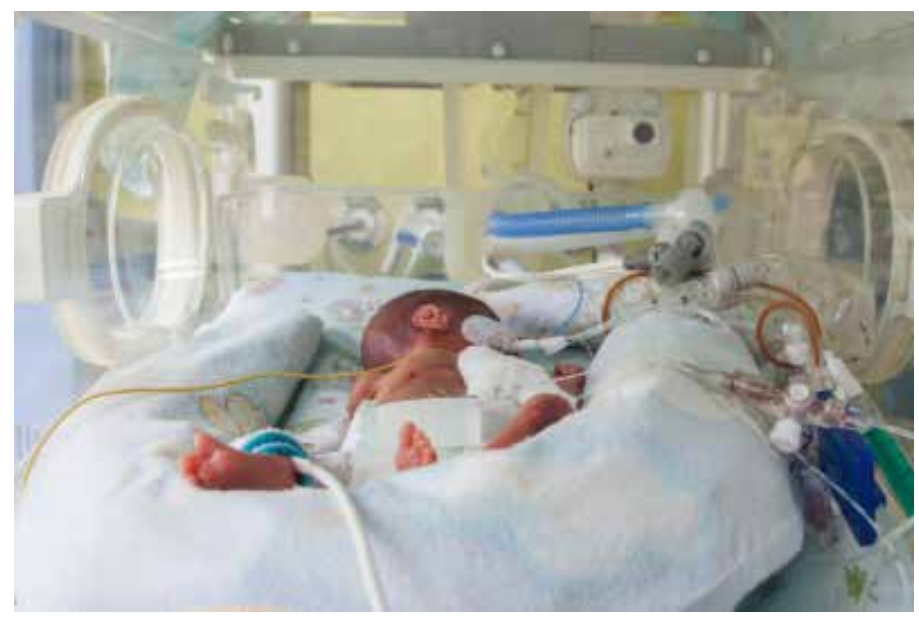

showed the realities of the disparities among African American families, the brutality of those disparities, and the racism on which they were created, the Alliance for Black NICU Families was our part of making infrastructural change specifically in the NICU parent and professional communities ongoing. It was beyond overdue and something I had spoken to during board and steering committee meetings regularly. I am not Black myself, but I saw too much that had yet to be addressed in our community, so I

\section{"Mayhem occurred at every entrance to the building resulting in "patriots" breaking through doors and windows and entering with every intent of "taking back the country." Like you, I watched how the Capitol Hill Police were outnumbered and overwhelmed."}

stepped up to do what was needed.

Fast forward to Wednesday, January 6, 2021, our nation's Capital came under siege as the 2020 electoral votes were being certified for then President-Elect Joe Biden. Mayhem occurred at every entrance to the building resulting in "patriots" breaking through doors and windows and entering with every intent of "taking back the country." Like you, I watched how the Capitol Hill Police were outnumbered and overwhelmed. I also watched as some of the officers were high-fiving rioters and taking selfies, too. In the aftermath, the Capitol Hill Police chief resigned, feeling he had failed his officers. As it turns out, he had been requesting help for many days and weeks ahead of the certification. His Pentagon bosses deemed it not necessary as one of them felt that the "optics looked bad." Seriously? Well, the scene looked way worse, as it turned out. It was horrific and also the very definition of White Privilege on full display. As the rioters looted and destroyed congressional offices as they beat officers with various weapons, others chose to

\section{National Coalition for Infant Health Values (SANE)}

Safety. Premature infants are born vulnerable. Products, treatments and related public policies should prioritize these fragile infants' safety.

Access. Budget-driven health care policies should not preclude premature infants' access to preventative or necessary therapies.

Nutrition. Proper nutrition and full access to health care keep premature infants healthy after discharge from the NICU.

Equality. Prematurity and related vulnerabilities disproportionately impact minority and economically disadvantaged families. Restrictions on care and treatment should not worsen inherent disparities. 
cement the moment in other ways with pictures alongside statutes as they waved a Trump 2020 flag or meandered down a hall with a large Confederate flag. For days I shook with anger and was equally devastated. I attended the Women's March in 2017 as 1.2 million people of every type of background attended and marched peacefully throughout the city filled with military trucks, tanks, and police vehicles. And note that all of this, plus full riot gear, rubber bullets, and tear gas was in place for the Black Lives Matter protests. The contrasts are glaringly apparent to this month's utter thuggery-shame on us.

So what does this blatant White Privilege have to do with Neonatology? A lot, as it turns out. Studies are now showing that Black newborn babies under the care of a white doctor are at a high risk of dying. $20 \%$ of the babies in the NICU are Black. Do the math. It is painful.

\section{"Add to this learning that my fellow Preemie Moms that were Black and the families they served never received any educational materials or given any sense of how to advocate for their child."}

Add to this learning that my fellow Preemie Moms that were Black and the families they served never received any educational materials or given any sense of how to advocate for their child. Knowing that she was at high risk for preterm birth, my co-founder found out that the $17 p$ shots were not going to be covered. She had to move states to get what she needed to help her baby have a safe start to life. I have one close friend whose son was supposed to be taken to the eye doctor for ROP follow-up, but no one had told the family at discharge. Today, he is blind, despite the family's heroic efforts after the fact. And, another family had security called on the father in the operating room as his wife had an emergency csection to save her life and that of the child just because he was asking questions. Imagine weeks later when this same family got a call from the NICU the morning of the baby's discharge date to tell them that their son died. All of these families were Black. Surreal.

White Privilege is receiving care without security being called. It

"White Privilege is receiving care without security being called. It is also getting the resources and educational materials needed to make informed decisions and appropriate follow-ups as well. It is not having to look over your shoulder all of the time while caring for your baby in the NICU." is also getting the resources and educational materials needed to make informed decisions and appropriate follow-ups as well. It is not having to look over your shoulder all of the time while caring for your baby in the NICU. It is not having to endure microaggressions and outright racist behavior from a NICU provider simply because you have a different skin color. Add to this the White Privileged Moms who have enough means to buy their baby needed items and access to specialized healthcare outlets and equipment as well as time off from work and/or childcare for appointments, etc. And do not even get me started on the lack of access to decent housing, food, and medications as well as jobs, benefits, and equal compensation. The stark difference is horrific and shameful. I was one of those privileged Moms, and I had no idea that this was a problem 17 years ago. White Privilege is assuming that everyone else is treated as well as you are. It is time for a change.

We need to do better for these families. Everyone entering the NICU deserves equal care, respect, equal access to help, and so much more. Racism is insidious, and if I hear from one more professional on social media that "Racism is not in our NICU," I will scream. Racism in the NICU happens quietly in rooms, behind doors with a word, a look, a feeling of unwelcome. It is not always the blatant encounters one sees in the movies.

Join us as we make real, positive change. Change happens when good people join hands in partnership and work together. The Alliance for Black NICU Families welcomes organizational partners across the country to help us mandate annual implicit bias training for NICU professionals state by state and endorses the Once Upon a Preemie Academy for its unique approach. We are also working to provide families and African American-led NICU/preemie organizations with grants to further their work.

Disclosures: Deb is a co-Founder of The Alliance for Black NICU Families (https:///blacknicufamilies.org), and the Founder of PreemieWorld, LLC (https://preemieworld.com) as well as Crystal Ball Health, LLC (https://crystalballhealth.com)

NT

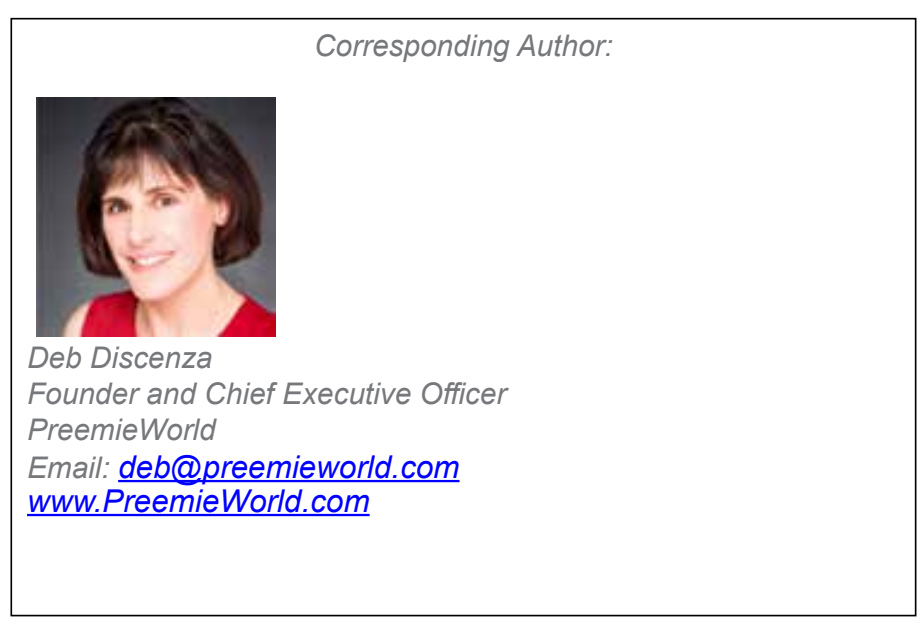

